\title{
The Experiences of the Inter-American Institute for Cooperation on Agriculture (IICA) in Supporting Rural Development in the Caribbean Region
}

\author{
Edric Harry \\ Inter-American Institute for Cooperation on Agriculture, Trinidad and Tobago
}

Copyright $\bigcirc 2016$ by authors, all rights reserved. Authors agree that this article remains permanently open access under the terms of the Creative Commons Attribution License 4.0 International License

\begin{abstract}
The Inter-American Institute for Cooperation on Agriculture is an International Organization that provides technical support for the development of agriculture and rural life in thirty- four countries in Latin America and the Caribbean, including Trinidad and Tobago. Over the years, there were mixed results in the Institute's programmes, designed to improve the lives and livelihoods of farmers and members of community groups living in rural areas. The degree of success enjoyed in delivering those programmes, and ease with which they were implemented depended, to a large extent, on the nature of problems besetting those communities, and facilitative environment provided at the institutional level. IICA also had favorable experiences in providing support to rural community groups which had requested support for further exploiting opportunities with potential for improving their income earning capacity. The paper, therefore, seeks to identify the nature of the challenges experienced by the IICA Office in providing support to community groups in Trinidad and Tobago and selected countries of the region, and to highlight interventions undertaken for assisting those communities. The paper further outlines conditions, both at the community and institutional levels, which can facilitate the technical cooperation process.
\end{abstract}

Keywords Rural Development, Cooperation on Agriculture, Inter-American Institute

\section{Introduction and Context}

\subsection{IICA's National Technical Assistance Programme}

The Inter-American Institute for Cooperation on Agriculture (IICA), is an International agricultural development Institute which falls under the Organization of American States (OAS) System. The Institute has Offices in 34 countries in Latin America and the Caribbean and very often works, with many other agricultural institutions and agencies to deliver technical assistance to stakeholders in the agrifood sector in the areas of agricultural trade and policy; agribusiness management; agricultural health and food safety and technology and innovation.

Assistance is also provided to farmers and community groups in preparing project proposals to access funding. Support is also given to institutions and organizations in developing sector plans and programmes. Many stakeholders along the agrifood chain also benefit from various capacity building and skills development training provided by the Institute.

The engagement by IICA with community groups and its effectiveness in the delivery of its technical cooperation programme is dependent on the nature of the challenges and opportunities existing at different levels in the agrifood sector. At the institutional level, the challenge encountered can be the product of the policies and programmes, instituted by the state which impact on community life.

At the community level, attempts to deliver technical assistance programmes to groups present a range of challenges which may be unique to the practices and way of life of the targeted communities while the IICA Office strives to surmount the challenges in dealing with groups, it also seeks to assist groups, within communities, to identify and explore opportunities that may be presented

\section{Objective of the Paper}

The paper seeks to highlight the work of IICA, both locally and regionally, in providing technical assistance for farming and community groups, within the context of the challenges posed and opportunities presented for providing such assistance.

\section{The Methodology}

The analysis involved the following:

- Identification of major challenges faced by farming 
and community groups in Trinidad and Tobago, with references made to selected countries in the region.

- Identification of the work IICA has been doing to contribute to resolving the challenges highlighted.

- Identification of conditions or success factors which facilitate the work of IICA in dispensing its programmes and projects to community and farmer groups.

\subsection{Challenges Encountered in Engaging Community Groups: Trinidad and Tobago}

\subsubsection{The Perception of Agriculture by the General Public}

The agricultural sector in Trinidad and Tobago has traditionally played a significant role in shaping the economic; social and cultural landscape of many rural communities. However, the sector's contribution to the economy, according to GDP statistics published by the Central Statistical Office, has been declining over the years. The statistic indicates that, in 2014, the sector contributed less than $1 \%$ to the country's GDP (Review of the Economy of Trinidad and Tobago (2014).

Unfortunately the GDP statistic, which is commonly used to gauge the contribution or worth of the sector by the general public, does not take into consideration the multifunctional nature of agriculture and its backward and forward linkages to other sectors of the economy. The contribution that agriculture makes to economic development is, therefore, underestimated. Failure to recognize and to accept the wider contribution of agriculture may be a factor that is taken into consideration by the general public in their relatively lower ranking of the agricultural sector. This skewed perception of the true contribution of the agricultural sector may also be linked to its inability to attract labour, and required level of investments and other resources, when compared to other sectors.

In an attempt to quantify the real contribution of the agricultural sector to the economy, IICA in 2006, undertook a study, using a Social Accounting Methodology. The results of the analysis showed, inter alia, that when the backward and forward linkages of the agrifood sector are considered, the sector's contribution increased from $2 \%$ of GDP to 8.65 . Very few persons, however, outside academic \%.(Harry, E. and O. Segura (2006), More than Food on the Table: Agriculture's True contribution to the Economy of Trinidad and Tobago, unpublishd).ia appreciated the research and its value in repositioning or changing the perception about the sector.

\subsubsection{Competition from Other Sectors}

There is a tendency for rural dwellers to rely less on agriculture and to seek alternative economic activities either to supplement income generated from part-time agriculture or to resort exclusively on non-agricultural activities for earning a livelihood. Income generated from farmers who are in agriculture on a part-time basis is becoming more and more a predominant practice in the farming economy. In this context, one could argue whether this category of farmers can dedicate the necessary time and resources to ensure that community-based programmes, if implemented, can be successfully completed.

Even rural communities with a long tradition of agriculture, as a mainstay, are now finding it very difficult to attract labour to sustain production. The situation also applies to children of farm families whose preferences are to seek employment in non-farm activities or in employment programs created by the state, such as the Community-Based Environmental and Enhancement Programme (CEPEP) and Unemployment (URP). Attracting and maintaining younger persons, in particular, into the agricultural sector is, therefore, becoming a major challenge in many rural communities. Of concern in this regard is an aging population and their capacity to continue managing their farms and community projects at optimum levels.

\subsubsection{Sustainability and Management of Groups}

There are also problems related to the sustainability or cohesiveness of many farmer groups and cooperatives: The functioning of many of these groups may breakdown as a result of issues ranging from: poor management and governance; lack of trust among members of groups; conflict among group members; lack of proper leadership and tendency for members to leave the group to pursue other options. There are instances when leaders of a group cannot continue and the group disbands since there are no other persons within the group with leadership capacity to succeed the outgoing leader to continue ongoing programmes and projects. Lack of succession planning in many of the community groups is, therefore, a major threat to the sustainability of community projects.

\subsubsection{Management Practices and Capacities of Groups}

Poor or non-existent record keeping among farmers and community groups can be considered a major challenge to taking many of the groups to the next level of the business spectrum. In a base line survey, conducted by IICA in collaboration with the Ministry of Food Production, among livestock farmers, for example, some of the respondents indicated that they either did not have the time to keep records or they did not value its importance. Some respondents also indicated that their operations were too small to merit keeping records.

In adequacies in the record keeping system implies that the groups are not be in a position to make the necessary production and financial decisions to improve their businesses or to sustain programmes. The absence of proper records also implies that many of the groups do not qualify to access loans and other resources from institutions which may require historical records as criteria.

\subsubsection{Securing Land, Buildings and Equipment for Community Projects}

Many community projects involve having access to resources, in particular, land and buildings and equipment) 
which are required for community or group projects. Such projects, for example, commonly involve the acquisition of land for construction of processing facilities; fish farming, and nurseries for crop production and for livestock activity.

Generally, two options are utilized by groups for accessing land: One option is to apply for state land for the community project. Accessing land from the state, however, may take a long time. Since the period between applying and eventual approval may be prolonged, some members of groups lose interest in the project and may consequently move on to some other activity. In this case, the planned community project the group wished to pursue is aborted. Group members also lose tend to interest in projects when applications for approvals from state agencies for project-related activities are protracted. Interest in community-based projects also tends to be lost when approvals for loans or grants take long periods of time.

In other cases, land for a community project may be donated by a group member for use by the group. This arrangement may not be legally binding and its sustainability depends on the strength of the relationship maintained between the group member who donated the land and other members of the group. If conflict arises between the two parties, there can be issues related to continued access of the facility or enterprise established on the land provided by the group member.

Conflict may also arise when vehicles and equipment, including tractors have been acquired for use by members of the community. Conflict can develop when the group does not establish clear and transparent rules for use and maintenance of equipment or when they fail to abide by the rules established for their usage.

\subsubsection{Buy-in from Other Members of the Community}

Successful implementation of some projects for a particular group within a community may require the support of other groups and stakeholders within that community, such as the village council other farmer groups, NGO'S and political party groups. The Office has had experiences of attempting to undertake work in communities, but was stymied in its efforts because of lack of support from other community groups and interest groups within the community. The projects, however, were short lived since they were not supported by other interest groups in the community.

Determining ownership of a community resource can also be a challenging experience especially in situations when one group in a community wishes to exploit such resources for themselves at the expense of other members of the community. Community Agro-tourism projects and projects that involve the institutional memory of a community are likely to have that challenge in implementation.

\subsubsection{Knowledge about Available Technical and Financial and Regulatory Services}

Many farmer groups and organizations are not very knowledgeable about organizations and agencies which can provide free technical and financial services for improving their effectiveness as a group. Specifically, these groups were found to have limited knowledge on institutions and agencies which provide information on grant funding; accessing markets; product development; technology and technological innovations; standards for packaging and labelling; entrepreneurship and group dynamics. Groups that fall in that category are likely to be at the lower scale of development and will require greater effort to make them more sustainable.

\subsection{Challenges Encountered in Engaging Community Groups in the Region}

\subsubsection{The Jamaica Experience}

- Lack of succession planning, particularly by some leader who are very strong: many of those leaders remain in office for long periods of time

- Some group members are unwilling to serve in leadership positions, resulting in some leaders serving for long periods of time.

- Leaders of some groups are volunteers who have other interests and may be unavailable at times to dedicate their time to the group

- Lack of trust among members of groups: an issue that often leads to the fragmentation or break up of groups

- Inability of groups to find means of becoming financially sustainable and dependence on sponsorship from the state and other donations

- Poor attendance of members at meetings( usually $20 \%$ of total membership)

\subsubsection{The Barbados Experience}

- A limited sense of ownership among farmers and community groups once government and or regional or international organizations agencies are partnering on the project

- Not all members of groups participate fully in implementing projects

- Waning interest by groups in class room type training workshops

\subsubsection{The Antigua - Barbuda Experience}

- Many groups lack capacities in the following areas: project proposal writing for funding; leadership skills; ICT and group dynamics

- Absence of groups in decision making processes

- Lack of community resources

\subsubsection{The Grenada Experience}

- Weak governance of groups

- Members of some groups are only interested in what they can receive and are not interested contributing to the group

- Persons may be appointed by some groups to executive positions but such persons may not have 
the required capabilities.

- Overreliance by some groups on organizations that were instrumental in their creation

- Lack of communication and knowledge sharing among members of some groups

- Some groups do not have an established secretariat

\section{Interventions Undertaken by IICA in Support of Agriculture and Rural Development}

Most of the interventions undertaken by IICA, generally in collaboration with other development partners in agriculture, are designed to empower and improve the capacities of rural groups so that they are better positioned to improve their lives and livelihoods and communities. Programmes and projects undertaken by the IICA Office, in support of community and rural development, operate at two levels: The institutional level and the community level. Interventions are often in response to the challenges and or needs identified by farmers and community groups.

At the institutional level, attempts are made to support and or to influence policies; programmes and projects of the Ministry of Food Production and other Institutions for improving the lives of farmers and rural community groups. Support, for example, was recently provided to the Tobago House of Assembly and Government of St Kitts and Nevis in developing their Agricultural Sector Programmes. The IICA Office attempts to influence and guide policies to promote community and rural development by participating in consultations hosted by the Ministry of Food Production and by providing frameworks and guidelines for policy and programme development.

At the famer and community group level, the emphasis is principally placed on improving the knowledge and skills of community groups through a range of interventions including workshops; seminars; meetings; exchange visits and skills development training. Many farmer and community groups have been exposed to training in the following areas:

- Entrepreneurship and management: to further empower groups to be more sustainable

- Group dynamics: To deal with the many conflict situations facing groups

- Marketing: with emphasis on accessing markets locally and externally

- Health and food safety: with focus on good agricultural and manufacturing practices, as well as proper techniques of packaging and labelling

- Record-keeping: with focus on determining the profitability of agricultural enterprises, and use of records for production, and investment and decision making

- Technology and innovation: with emphasis on machinery, equipment and software systems available for small scale processors and producers.

- Resource mobilization: with emphasis on exposing farmers and community groups to project proposal writing for accessing grants, technical support and other resources.

- Events planning and management: With the objective of improving the capacity of community groups to better plan and execute many of the community events such as food festivals such as the mango festival ; cultural and sporting events

- Information, communication and technology: some communities benefitted from computers donated by the office

- Product development: Efforts to add value to primary products is assuming greater significance in many farming and rural communities. In response to this growing demand, the IICA Office has been organizing skills development, hands-on training, to develop the capacities within groups to develop the following value-added products: cheese and yogurt from goat's milk; bread and other bakery products from cassava and other root crops, as well as training in producing specialized cuts from goat and sheep meat.

Support had also been provided to communities in adding value to the cocoa produced in communities. At least two communities are now producing and selling dark chocolate, with their own trade names, which includes the names of their communities. The two communities are reporting that by adding value to their cocoa, their income generating capacities have improved and interest in producing cocoa within their communities has increased.

Agro-tourism is another product that many members of community groups have identified as a source for 'generating income. The IICA Office has provided support in this area, by preparing project proposals for acquiring resources for training of two community groups involved in agro-tourism and by sending members to Mexico to participate in agro-tourism courses. The extent to which the IICA Office can accommodate requests for this activity, however, is limited since assistance provided by the Office is mainly for group or community activity, while requests for support principally come from individuals for assistance in developing their particular estates.

Further, the issue of developing a project that involves use of a community resource also presents a challenge. The difficulty stems from determining who has rights to the resource, as well as how should the proceeds generated from the use of such resources be equitably distributed to the community. The Office has discovered that projects involving community resources, including intellectual property, may present some difficulty unless there is a clear understanding and agreement by the community for utilizing such resources for the benefit of all. 


\section{Prerequisites for More Effective Technical Cooperation Programmes}

IICA's efforts in supporting community groups may have a greater impact if the following conditions exist at the institutional and community levels:

At the Institutional Level, success in implementing projects with communities can be higher if there are:

- More consistent and effective agricultural policies and programmes instituted by the state to facilitate production; productivity and investments in the sector. Specifically, the type of policies and programmes preferred are those that will encourage greater flow of resources and use of technologies for improving farm infrastructure, as well as research.

- Policies to minimize risks which farmers in communities may face such as: marketing and financial risks; praedial larceny and crop and livestock failure due to climate change

- Policies to encourage greater private sector investments and partnerships in the agrifood sector

- Systems in place for greater collaboration among development partners involved in community development

At the Community level, success in providing support to groups can be higher if farmer groups:

- Are more organized and show greater commitment to participate in

- Community oriented activities

- institute measures to become more sustainable, unified and accountable

- Forge greater partnerships and networks with other faming and community groups

- Arrive at consensus on what community projects best serve the interest of the community

- Adopt a more business-like and entrepreneurial approach to managing their community projects

\section{Approaches by IICA}

The Office tends to develop and maintain long term relationships with community groups it has provided assistance. The relationship may extend to inviting the groups to special events being hosted by the Office or by accepting invitations to attend functions organized by groups within their communities. The Office also allows many groups to use its office facilities for hosting their meetings and training sessions. These groups include: The Network of Rural Women Producers, The Tilapia Farmers Association; The Goat and Sheep Association; and The Organic Agriculture Association.

It is observed that maintaining long term relationships with groups creates greater trust with the Office. This type of relationship makes it easier to get the groups involved in projects the Office wishes to promote in their communities.
Trust is developed over time by paying attention to the needs of groups and by following up on their requests for assistance and support.

The Office also involves community groups in developing projects for funding: Members of community groups are usually met in their communities, either in community centres, schools or at the home of a member. A frame for the project proposal is usually provided and each member of the group is allowed to discuss and provide the information required. In the event that members cannot provide the information, they are required to research and provide it for the next meeting. Such group interactions continue until the entire project is completed.

The Office has observed that the participatory approach to preparing projects not only builds some capacity within the groups for preparing future projects but the process creates greater interest and fosters greater teamwork and partnerships among members of the group.

\section{Conclusions}

The extent of the success or effectiveness of the programmes and projects delivered by IICA, in support of promoting agricultural and rural development, in the Region and in Trinidad and Tobago, in particular, depend on the nature of challenges confronting rural community groups, as well as the facilitative environment created through policies of the State.

It would appear that Community groups which are strong and well organized benefit the most from projects, capacity building programmes and other resources provided by IICA. On the other hand, groups which are not as strong, and with less capacity benefit less from resources that can be provided. The latter groups are also less likely to succeed in managing projects offered by IICA. There are many community groups in the latter category so that one can conclude that there still remains a significant amount of work to be done to empower rural community groups to become more prosperous and sustainable.

Further, the task of improving the lot of rural communities, through agricultural programmes, is also onerous given the tendency for young persons and others within communities to be attracted to work outside their communities.

There is also scope for improving the collaboration with policy makers and for working closer with other agencies involved in rural development to ensure that the appropriate facilitative environment is in place at the institutional level to promote growth and prosperity of community groups.

Notwithstanding the many challenges, there are encouraging signs that some community groups involved in the agrifod sector are taking steps to improve their livelihoods as evidenced by producing more and improved value added products from primary agricultural products and by attempting to access new markets and by networking among themselves. 


\section{Acknowledgements}

I wish to extend sincere thanks to my IICA colleagues in the region for the information they provided on IICA's experiences in providing technical support to communities in their countries.

These persons include:

Mr. Ainsworh Riley - IICA Office, Jamaica

Mr. Derek Charles - IICA Office, Grenada

Mr. Craig Thomas - IICA Office, Antigua and Barbuda

Mr. Damien Hinds - IICA Office Barbados

\section{REFERENCES}

[1] Ministry of Finance, Trinidad and Tobago, Review of the Economy of Trinidad and Tobago (2014)

[2] Harry, E. and O. Segura (2006), More than Food on the Table: Agriculture's True Contribution to the Economy of Trinidad and Tobago, unpublished 